( 2019 , The Authors. Published by FASS Inc. and Elsevier Inc. on behalf of the American Dairy Science Association ${ }^{\circledR}$. This is an open access article under the CC BY-NC-ND license (http://creativecommons.org/licenses/by-nc-nd/4.0/).

\title{
Lameness during the dry period: Epidemiology and associated factors
}

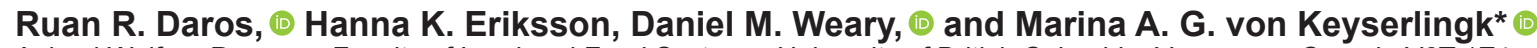 \\ Animal Welfare Program, Faculty of Land and Food Systems, University of British Columbia, Vancouver, Canada V6T 1Z4
}

\begin{abstract}
Lameness has been extensively studied in lactating cows, whereas few studies have reported on lameness during the dry period. We conducted a prospective longitudinal study to describe the epidemiology of lameness during the dry period and to identify risk factors associated with onset, cure, and chronic cases of lameness. A total of 455 cows from 6 freestall commercial dairy farms were enrolled at $9 \mathrm{wk}$ before calving and gait scored weekly until calving using a 5-point scale. A subset of cows was also followed fortnightly after calving to measure the association between lameness during the dry period and lameness during early lactation. Body condition score (BCS) was assessed in a 5 -point scale using increments of 0.5 . Hoof-trimming records, parity, and previous lactation milk production were retrieved from farm's database. Cows were considered sound when 2 consecutive scores were $\leq 2$ and lame when 2 consecutive scores $=3$, or any assessment with score $>3$; when in a sequence of scores only one score $=3$ (or $\leq 2$ ), the cow was considered sound (or alternatively lame). Following this lameness definition, we derived weekly lameness status for each cow and calculated the number of new cases of lameness, the number of cure cases and the number of chronic cases. The incidence rate of lameness cases during the dry period was 8.2 lameness cases/100 cow per wk, whereas cure rate was 7.1 cure cases/100 cow per wk; at the end of the dry period $50 \%$ of cows had developed lameness and $36 \%$ were cured. Multilevel logistic regression models using farm as random effect were fitted to assess (1) the association between being lame in wk 2 or 8 postcalving with being lame in the last week precalving, (2) risk factors for lameness onset, (3) risk factors for lameness cure, and (4) risk factors for chronic lameness. Cows that were lame in the week immediately before calving were more likely to be lame in wk 2 and 8 after calving. We found that the interaction between parity and hoof-trimming before dry-off was associated with
\end{abstract}

Received April 3, 2019.

Accepted August 8, 2019.

*Corresponding author: nina@mail.ubc.ca lameness onset; primiparous cows that were trimmed before dry-off had lower odds of developing lameness, whereas the opposite was found for multiparous cows. The same interaction was also associated with the odds of chronic lameness. Cows that were diagnosed with noninfectious hoof lesions compared with cows that were not diagnosed with hoof lesions before dry-off, and cows that had BCS $<3$ compared with cows with BCS 3.0 to 3.5 at dry-off had higher odds of chronic lameness. Conversely, primiparous cows and cows with BCS 3.0 to 3.5 had higher odds of curing lameness during the dry period. Our results suggest that the dry period may be a period of high risk for lameness development and that hoof-trimming before dry-off may not be effective for all cows.

Key words: lameness risk, claw trimming, dairy cattle

\section{INTRODUCTION}

Lameness is a painful condition (Chapinal et al., 2010) that affects 20 to $55 \%$ of indoor-housed dairy cows in North America (von Keyserlingk et al., 2012; Solano et al., 2015). This malady has been shown to decrease milk production (Green et al., 2002; Archer et al., 2010), decrease reproductive performance (Hernandez et al., 2005; Bicalho et al., 2007), and increase involuntary culling (Booth et al., 2004). Though lameness can occur at any stage of a cow's life, the majority of work has focused on lactating cows. There is, however, no consensus as to when during lactation cows are at greatest risk for lameness. For example, Bicalho et al. (2007) found lameness to be more prevalent during the first weeks of calving, whereas Green et al. (2002) reported greater lameness prevalence in the 2 to 3 mo after calving. Last, in an observational study including dry cows, Calderon and Cook (2011) found lameness to be highly prevalent during the dry period.

Most studies on lameness have reported lameness prevalence, thus failing to provide information about when, and how many, new lameness cases arise or are cured. In the United Kingdom, where a few herds were regularly assessed for lameness (see Randall et al., 2015 for herd description), lameness incidence ranged from 1.4 to 7.4 cases of lameness per cow/year (Randall et al., 2018). Lameness cure is rarely reported; Lim et al. 
(2015) reported cure risk during lactation of $81 \%$, with most $(88 \%)$ curing from lameness within $45 \mathrm{~d}$. Archer et al. (2010) reported that from cows gait scored in the months immediately before and after the dry period, $57 \%$ of cows remained lame, $18 \%$ recovered from lameness during the dry period, and 16\% developed new cases. There is a dearth of information about how lameness develops in nonlactating cows.

Lameness is usually caused by claw lesions (Murray et al., 1996; Tadich et al., 2010), which are commonly treated by hoof-trimming (see review by Potterton et al., 2012). However, the success of hoof-trimming treatment depends on the type of lesion (Miguel-Pacheco et al., 2017) and lameness duration (Thomas et al., 2016). Hoof-trimming can be used as a preventive strategy for lameness (Manske et al., 2002); thus, some industry organizations recommend hoof-trimming 2 mo before calving (Dairy Farmers of Canada, 2009).

Other factors have been associated with the development of lameness. For example, thin cows are more likely to become lame compared with cows that maintain good body condition (Randall et al., 2015, 2018). Moreover, older cows, cows that produce more milk, and cows with a previous history of claw lesions are more likely to be lame (Green et al., 2002; Hirst et al., 2002; Lim et al., 2015; Randall et al., 2018).

The aims of this study were 3 -fold: (1) to measure the incidence and cure of lameness during the dry period, (2) to measure the association between lameness during the dry period and in the weeks after calving, and (3) to describe risk factors associated with onset, cure, and chronic cases of lameness during the dry period.

\section{MATERIALS AND METHODS}

This study is part of a large project encompassing several observational studies regarding lameness during the dry and early lactation periods. The project was approved by the Animal Care Committee at the University of British Columbia (protocol A15-0084). Data were collected from May 2017 to January 2018.

Number of cows available for data analysis of the current study was set by the sample size required for another study performed within the same project; thus, no power calculation was undertaken for the specific objectives of the current study.

\section{Farm Enrollment Criteria}

Through a partnership with a local hoof-trimming company (AR-PE Hoof Trimming Ltd., Abbotsford, Canada), commercial farms in the lower Fraser Valley, British Columbia, Canada, were selected following several criteria: $\geq 160$ lactating cows, freestall housed herd, individual records of cows, and willingness to participate in the study. In total 13 farms were contacted, 9 agreed to participate; however, for logistical and scheduling reasons only 6 were used in the current study. Cows from participating farms were routinely hoof-trimmed by 1 of 3 certified hoof-trimmers from the same trimming company. In this prospective longitudinal project, cows were enrolled continuously; thus, herds were visited according to the data collection schedule, as described below.

\section{Farm Description}

Detailed description of the enrolled farms and farm management practices are provided in Table 1. Farm characteristics were recorded through a structured interview with the herd manager. Variables related to barn structure (e.g., flooring type and feed-space per pen) were assessed through an environmental inspection performed during the first farm visit. Selected farms milked on average $361 \pm 137$ (SD) cows with an average milk yield of $11,866 \pm 1,579 \mathrm{~kg}$ of milk per lactation. Lactating cows were kept in freestall barns with either concrete flooring $(\mathrm{n}=5)$ or slatted floors ( $\mathrm{n}$ $=1$ ). On one farm the far-off cows had outdoor access during the summer (from June to September). Standard practice on all farms was to dry off cows approximately 2 mo before their expected calving date. Lactating herd lameness prevalence was assessed during the first farm visit when cows were gait scored when exiting the milk parlor following the 5-point methodology described by Flower and Weary (2006). One of 2 trained observers (RRD and HKE) scored the cows on all participating farms. Cows were considered lame when gait score $\geq 3$; all others were considered sound. Details on interobserver reliability are provided below.

\section{Cow Enrollment and Data Collection}

A total of 465 parous cows with expected calving dates between July 21 and December 1, 2017, were initially enrolled in the study. Data collection for each cow started at wk 9 before expected calving date. Cows were gait scored (details below) weekly until calving; cows that lost their ear tags $(n=2)$, died $(n=1)$, were sold $(\mathrm{n}=3)$, calved too early $(\mathrm{n}=3)$, or were reluctant to stand up because of severe lameness $(\mathrm{n}=1)$ were excluded from the study, resulting in 455 cows with complete data sets during the dry period.

After calving, only a subset of cows $(\mathrm{n}=307)$ had 2 gait assessments until wk 2 or 3 ; these cows were used for the analysis and the remaining cows with only 1 score were dropped. Within the cohort of 307 cows, 95 cows were followed until wk 8 or 9 after calving; 
Table 1. Farm characteristics and management for the 6 participating farms (all located in the Fraser Valley region, British Columbia, Canada) on the study of the epidemiology of lameness during the dry period

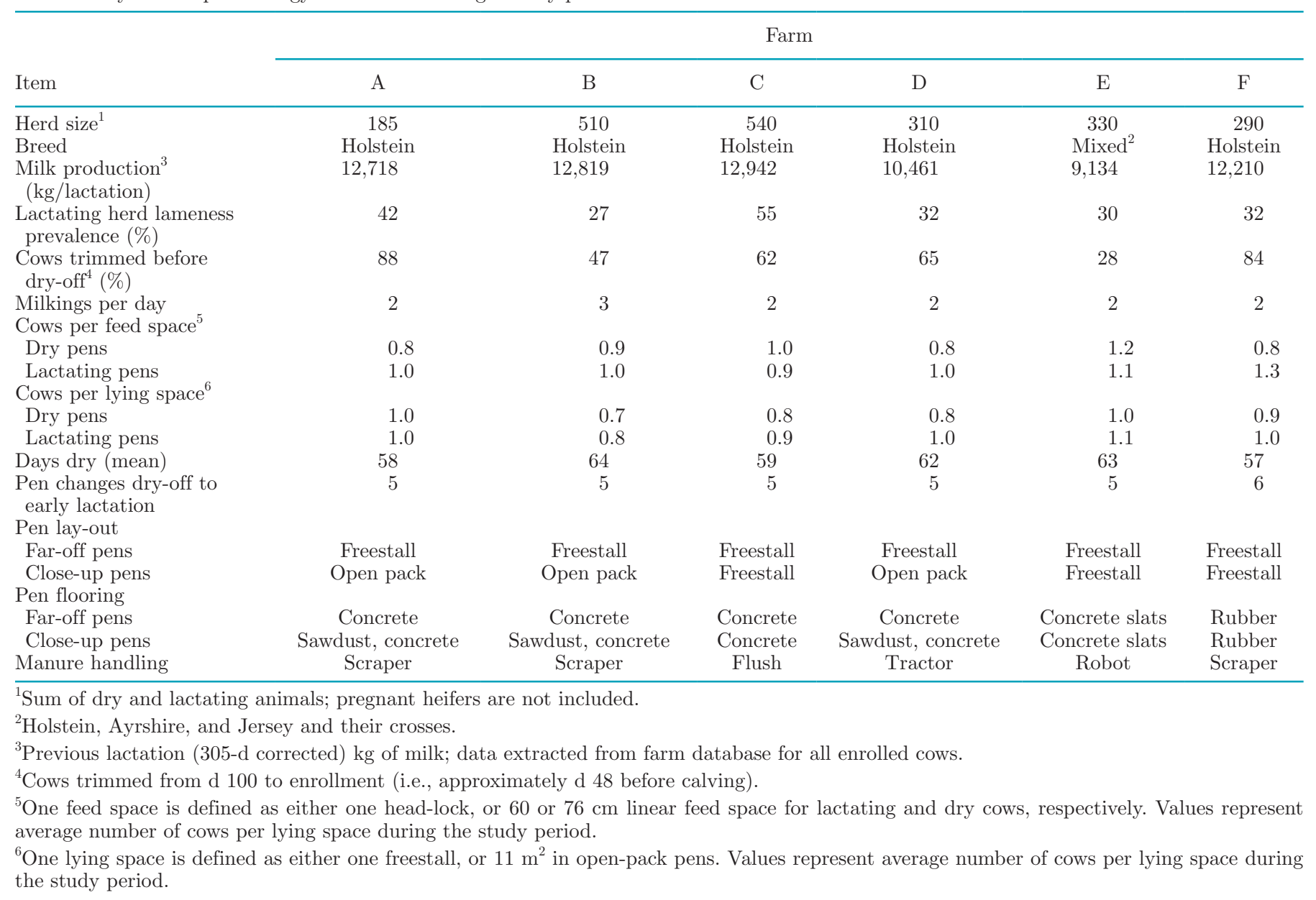

however, this group of cows was part of another study assessing the first case of claw horn lesions, which only included cows without previous history of claw horn lesions.

\section{Hoof-Trimming Records}

Lesion and treatment records were recorded using Hoof Supervisor System software (KS Dairy Consulting Inc., Dresser, WI) by 1 of 3 hoof-trimmers trained to use the Alberta Dairy Hoof Health Project's Lesion Severity Scoring Guide (www.dairyhoofhealth.info/Lesion -Severity-Guide-v0.7.pdf). Individual cow ear-tag numbers, presence of lesion, type of lesion, and date of trimming were retrieved from each farm from a database containing all trimming records for the year 2017.

Hoof-trimmings performed from d 100 before calving to the day of calving were retrieved for each enrolled cow. Hoof-trimming data were summarized by cow per trimming event; a cow was considered affected when at least one lesion was recorded. Lesion types were categorized as noninfectious lesions (including severe sole hemorrhages, sole and toe ulcers, white line disease, peripole ulcers, and thin soles) or infectious lesions (including digital and interdigital dermatitis, and foot rot). Trimming records were retrospectively split between periods, before enrollment (from d 100 before calving to enrollment) and after enrollment. If the cow was trimmed more than once before enrollment, the data from the trimming closest to enrollment date were used. In cases where there were multiple trimming records per cow after enrollment, only the most severe lesion score was retained.

Cows that were not hoof trimmed between d 100 before calving and calving day were assigned as not trimmed. With the exception of one farm, all reported that cows were trimmed shortly before dry-off. However, during our observations it became apparent that some cows were not trimmed before dry-off. This information is included in Table 1. Hoof-trimming occurred 


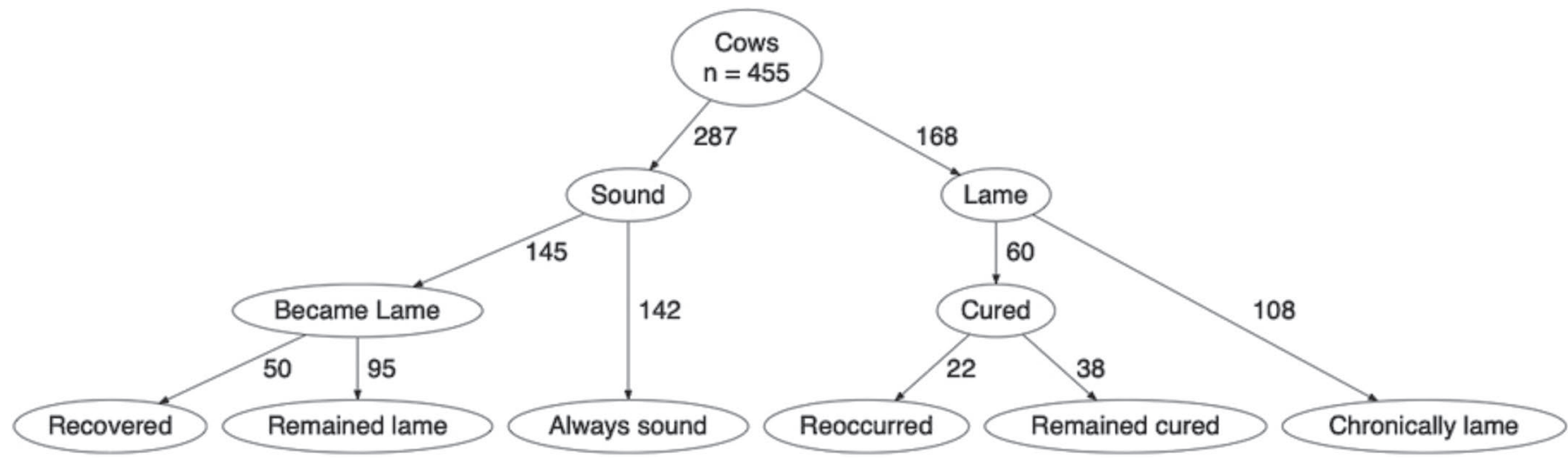

Figure 1. Diagram of lameness status during the dry period of dairy cows. Numbers represent the total of cows in each lameness status category. From top to bottom: total cows with complete data for the dry period $(\mathrm{n}=455)$; lameness status at first assessment; first lameness status change; final category based on last lameness status assessed in the week of calving.

on average $21 \mathrm{~d}$ before dry-off $(25$ th percentile $=9 \mathrm{~d}$, 75th percentile $49 \mathrm{~d}$ before dry-off).

\section{Gait Scoring and Lameness Definition}

On each visit, gait scoring was performed by 1 of 2 trained observers (RRD and HKE), blind to the hoof-trimming records. A detailed description of training and interobserver reliability between the observers is reported in a companion paper by Eriksson et al. (2019). In brief, both observers scored cows on all farms. Interobserver agreement was calculated using the quadratic weighted kappa (Cohen, 1968). Resulting kappa values were 0.84 for scores from video recordings and 0.57 and 0.55 from live scoring performed at the beginning and after the end of the data collection period, respectively. Systematic bias between observers was measured using the bias index (Byrt et al., 1993), resulting in values very close to zero, indicating no systemic bias between the observers.

Cows were individually walked in the pen by the observer, and gait scored from behind using the 5-point scale described by Flower and Weary (2006). A cow was considered lame if she had 2 consecutive gait scores of 3 or had one gait score $\geq 4$ (validated by Eriksson et al., 2019). Conversely, a cow was considered sound (or cured from lameness) if she had 2 consecutive gait scores $\leq 2$. In cases where only one of the gait scores was $=3$, for instance when a cow had consecutives scores of 2, 2, 3, 2,2 , the cow was considered to be sound throughout. Likewise, for a sequence of gait scores of $3,3,2,3,3$, the cow was considered to be lame throughout.

From these criteria we assigned a weekly lameness status for each cow. Based on the sequence of lameness status during the dry period each cow was categorized as follows: chronically lame (cows lame for the whole dry period), always sound (cows sound for the whole dry period), became lame (cows initially categorized as sound but becoming lame at any time during the dry period), or cured (cows that were initially lame and became sound at any time during the dry period). Cows that became lame, were further classified into remained lame (cow was lame on the last assessment before calving) or recovered (cows were sound on the last assessment before calving). Likewise, cows that cured were further categorized as remained cured (cow was cured on the last assessment before calving) or reoccurred (cow was lame in the last assessment before calving; Figure 1).

When severe lameness was identified it was reported immediately to the farm personnel, but we do not know if any treatment was provided.

\section{Other Cow Variables}

Body condition score ( 1 to 5 ) was assessed using 0.5 increments following Ferguson et al. (1994). Body condition score was assessed fortnightly, starting 1 wk after enrollment. BCS was categorized as $<3.0=$ thin, 3.0 to $3.5=$ good, and $>3.5=$ fat. The BCS was assessed by 4 jointly trained observers. Interobserver agreement between observers was calculated using the intra-class correlation (ICC), through 2-way and agreement methods (Hallgren, 2012). The ICC value of 1 indicates excellent agreement and value of 0 indicates agreement no better than chance; the calculated ICC for the 4 observers was 0.81 (95\% CI: 0.73-0.87) indicating good to excellent agreement (see Cicchetti, 1994).

Parity at enrollment was categorized as either primiparous or multiparous. Previous lactation milk production for each cow ( $\mathrm{kg}$ of milk per lactation - 305d corrected) was retrieved from the farms' database. Indi- 
vidual milk production was further centered and scaled; values used in the models represent standard deviation from the mean milk production of enrolled cows.

\section{Statistical Analyses}

Statistical analyses were performed in R 3.5.0 (RStudio Team, 2016; R Core Team, 2019). List of statistical packages, full statistical analyses code, and output are provided as Supplemental File S1 (https://doi.org/10 $.3168 /$ jds.2019-16741). The data used for this study and the code used to generate supplemental material are available at https://doi.org/10.5683/SP2/YTZMKX.

Lameness prevalence at wk $-8( \pm 1 \mathrm{wk})$ in relation to the calving date was calculated as the number of cows that were classified as lame (using the criteria defined above) at wk $-8( \pm 1 \mathrm{wk})$ in relation to the calving date divided by the number of cows enrolled in the study. Lameness prevalence at calving was calculated as the number of cows classified as lame at the last gait score before calving divided by the total cows enrolled in the study. Similarly, postcalving phases prevalence were calculated based on the lameness status assigned at approximately wk $2( \pm 1 \mathrm{wk})$ and wk 8 ( $\pm 1 \mathrm{wk})$ divided by the respective number of cows assessed in the same period.

Lameness incidence risk (i.e., cumulative incidence) during the dry period was calculated as the number of cows that became lame during the dry period divided by the number of sound cows at the beginning of the study period. Lameness cure risk during the dry period was calculated as the number of lame cows that cured lameness during the dry period divided by the number of lame cows at the beginning of the study period. Further classification was done for cows that became lame and cured of lameness sometime during the study period (see Figure 1). As such, incidence risk for the categories recovered and reoccurred were derived from the number of cows that became lame and cured, respectively.

Reporting rates allows for comparisons across studies; thus, we also calculated lameness incidence rate and cure rate. Rates were calculated as the number of new cases of either lameness or lameness cure divided by the total number of weeks at risk, multiplied by 100. If a cow had multiple cases of lameness or lameness cure, all cases were considered in the calculation. Number of weeks at risk per cow was calculated using the exact method as suggested by Dohoo et al. (2012), assuming that lameness (onset and cure) started at the midpoint between 2 consecutive visits.

A series of multilevel models (described below) were built to address the aims of our study. For all models, multicollinearity among variables was assessed through variation inflation factor; values $>3$ were considered multicollinear except for interaction terms and their main effects (as they inherently would have a degree of structural collinearity). Variation inflation factor for main effects were never greater than the set threshold and interaction terms were never $>4$. Models were tested for goodness of fit using the Hosmer-Lemeshow test (number of groups = 10; Hosmer and Lemeshow, 1980). The lowest Hosmer-Lemeshow chi-squared test $P$-value was 0.5 , thus indicating that models fit the observed data. Selection of predictors to be included in the models was based on causal diagrams; no variable reduction procedure was used for the main effects. Sometimes a categorical variable had too few observations per level $(\leq 5)$, impairing the estimation of its fixed effect standard error; in these cases, observations were either combined within another category or removed from the data and the model was re-fitted. Details for each of these cases are provided below. Biologically plausible interactions were included in the model using manual forward selection and were only kept in the model if $P$ $<0.05$. If including the interaction term caused failure in model convergence, the interaction and its main effects were explored in a separate model. The list of potential predictors available to be included in the models and their descriptive statistics are presented in Table 2. Different hoof-trimmers serviced different farms, so any effect of trimmer was accounted for in our random effect of farm in the models. It was not the aim of the current study to evaluate herd-level variables; thus, herd-level variables were not included in the models.

To measure the association between lameness diagnosed during the dry period with lameness at wk 2 ( $\mathrm{n}=307$ cows $)$ and wk 8 postcalving $(\mathrm{n}=95$ cows $)$, multilevel logistic regressions were fitted using lameness (binary: sound $=0$ and lame $=1$ ) at wk 2 and 8 as the outcome. Predictors included the main effect of lameness status at calving (binary: sound $=0$ and lame $=1$ ) and parity at enrollment. Tables showing model parameters are included as supplemental material (Supplemental Tables S1 to S4; https://doi.org/10 .3168/jds.2019-16741).

Multilevel logistic regressions with farm as random effect were fitted to assess risk factors for (1) lameness onset (binary: always sound $=0$, remained lame $=1$ ); (2) lameness cure (binary: chronically lame $=0$, remained cured $=1$ ); and (3) chronic lameness (binary: always sound $=0$, chronically lame $=1$ ) during the dry period. Cows categorized as recovered or reoccurred were not used for these models as we predicted that they would add noise to the data, given that they both cured and became lame during the dry period. Detailed 
description of the models used to assess risk factors for the onset, cure, and chronic lameness are provided below.

Models: Lameness Onset. Two different models were fitted to assess risk factors for lameness onset. The first included a subset of 237 cows (all always sound, and all remained lame cows), and set out to assess the association between hoof-trimming before enrollment (yes vs. no) and the onset of lameness; this model also included, parity, milk production, BCS, and the interaction between hoof-trimming before enrollment and parity. The second model included only cows $(\mathrm{n}=104)$ that were hoof-trimmed before enrollment and assessed the association between having a hoof lesion, or not, before enrollment and the onset of lameness. From the subset of 104 cows available for this latter model, only 2 cows had noninfectious lesions; hence, we combined different types of lesions into one category, encompassing cows that had either noninfectious or infectious lesions. Given that only 5 cows had BCS $<3$, we removed these cows from the subset and fitted the model using data from 99 cows. This model included parity, hoof lesion, milk production, and number of days elapsed since trimming as predictors in the model.

Models: Lameness Cure. Only one model was fitted to assess risk factors for lameness cure during the dry period. Data used for this model included 146 cows (all chronically lame and all remained cured cows). This model included parity, milk production, BCS, and hooftrimming before enrollment as predictors. We were not able to fit a second model to assess the association between type of lesion before enrollment and lameness cure, due to limited numbers of cows ( $\mathrm{n}=76$ cows $)$, which prohibited model convergence for BCS and lesion type.

Models: Chronic Lameness. Two models were fitted to assess risk factors for chronic lameness. The first model included data from 250 cows (all always sound and all chronically lame cows) and set out to assess the association between hoof-trimming before enrollment (yes vs. no) and chronic lameness. This model also included parity, milk production, BCS, and the interaction between hoof-trimming before enrollment and parity. The second model included only cows that were hoof-trimmed before enrollment $(\mathrm{n}=120)$; however, due to the low number of thin cows $(\mathrm{BCS}<3)$ we were required to drop these animals, leaving a final data set of 110 cows. Predictors included in this model were parity, type of lesion before enrollment, milk production, and days elapsed from hoof-trimming to enrollment.

\section{RESULTS}

\section{Epidemiology of Lameness and Hoof Lesion Prevalence During the Precalving Period}

The prevalence of lameness and severe lameness at dry-off $(\sim$ wk -8 ; Figure 2$)$, the week of calving (Figure 2 ), in the early postcalving period (wk 2), and around peak lactation (wk 8) are presented in Table 3. The prevalence of hoof lesions in the $100 \mathrm{~d}$ before calving and the proportion of cows trimmed before and after enrollment are presented in Table 4.

The incidence risk for each lameness status category (see Figure 1) and average number of weeks lame per lameness category are described in Table 5. Lameness

Table 2. List of potential predictors to be included in the models for assessing risk factors for the onset, cure, and chronic lameness in 455 cows from 6 dairy farms in the Fraser Valley region, British Columbia, Canada

\begin{tabular}{llcc}
\hline Variable & Type & $\begin{array}{c}\text { No. of } \\
\text { cows }\end{array}$ & $\begin{array}{c}\text { Proportion }(\%) \\
\text { or mean }( \pm \mathrm{SD})\end{array}$ \\
\hline $\begin{array}{l}\text { Parity at enrollment } \\
\text { Primiparous }\end{array}$ & Categorical & 162 & 36 \\
$\quad$ Multiparous & & 293 & 74 \\
BCS at enrollment & Categorical & 35 & 8 \\
$\quad 3.0$ & & 302 & 76 \\
3.0 to 3.5 & Continuous & 118 & 26 \\
$>3.5$ & & 454 & $11,860( \pm 2,573)$ \\
Milk yield (kg/lactation) & Categorical & 205 & 45 \\
Hoof trimming & & 44 & 10 \\
Before enrollment & & 206 & 45 \\
After enrollment & Categorical & 26 & 13 \\
$\quad$ Not trimmed & & 26 & 13 \\
Hoof lesions & & 153 & 74 \\
Noninfectious lesions & Continuous & 205 & $20( \pm 12.3)$ \\
Infectious lesions & & & \\
No lesion & & & \\
Days elapsed from trimming to enrollment & & \\
\hline
\end{tabular}


Table 3. Parity and total prevalence of lameness and severe lameness around dry-off (wk -8$)$, in the week of calving (wk 0), early postcalving (wk 2), and around peak lactation (wk 8) of 6 dairy farms in the Fraser Valley in British Columbia, Canada

\begin{tabular}{|c|c|c|c|c|}
\hline Period & Condition category & Primiparous $^{1}$ & Multiparous & Total \\
\hline \multirow[t]{2}{*}{$\mathrm{Wk}-8$} & Lameness (\%) & 9 & 28 & 37 \\
\hline & Severe lameness (\%) & 1 & 7 & 8 \\
\hline \multirow[t]{2}{*}{ Wk 0} & Lameness (\%) & 12 & 38 & 50 \\
\hline & Severe lameness (\%) & 3 & 8 & 11 \\
\hline \multirow[t]{2}{*}{ Wk 2} & Lameness (\%) & 12 & 34 & 46 \\
\hline & Severe lameness (\%) & 2 & 7 & 9 \\
\hline \multirow[t]{2}{*}{ Wk 8} & Lameness (\%) & 16 & 21 & 37 \\
\hline & Severe lameness (\%) & 4 & 3 & 7 \\
\hline
\end{tabular}

${ }^{1}$ Parity at the time of enrollment.

incidence rate from enrollment to calving was 8.2 cases/100 cows per wk and the cure rate from enrollment to calving was 7.1 cases/100 cows per wk. The majority of cows that became lame had 1 new case of lameness during the dry period and only 11 cows had 2 new cases of lameness during the same period. Cows with multiple new cases of lameness were all lame at calving. Likewise, most of the cows that cured had 1 cure case during the dry period, whereas only 4 cows had 2 cure cases during the same period. Cows with multiple cure cases of lameness were all sound at calving. The distribution of new cases of lameness and cure cases across the dry period are presented in Figure 3.

\section{Association Between Lameness Before and After Calving}

Cows that were lame immediately before calving had increased odds of being lame in wk 2 [odds ratio $(\mathbf{O R})$ $=37.0 ; 95 \%$ CI: 18.8 to $78.4 ; P<0.01]$ and wk 8 (OR $=4.5 ; 95 \%$ CI: 1.8 to $12.0 ; P<0.01$ ) after calving. Parity was not associated with odds of being lame in either of the postcalving phases. The details from these models are provided in Supplemental Tables S1 and S2 (https://doi.org/10.3168/jds.2019-16741).

\section{Risk Factors for Lameness Onset}

The interaction between parity and hoof-trimming was associated with the onset of lameness (see Figure 4a and Table 6). Multiparous cows had higher odds of becoming lame if they were trimmed before enrollment, whereas primiparous cows had lower odds of becoming lame if they were trimmed before enrollment. Milk production and BCS at enrollment were not associated with the odds of becoming lame.

In the second model, which included only cows hooftrimmed before enrollment, only parity was associated with the onset of lameness. Multiparous cows had 10 times the odds ( $95 \%$ CI: 3.7 to $40.2 ; P<0.01$ ) of be- coming and remaining lame during the dry period compared with primiparous cows. Having a hoof lesion (OR $=2.0 ; 95 \%$ CI: 0.5 to $10.4 ; P=0.38)$, days elapsed from hoof-trimming to enrollment ( $\mathrm{OR}=1.0 ; 95 \% \mathrm{CI}: 1.0$ to 1.1; $P=0.85)$, and previous lactation milk production $(\mathrm{OR}=0.7 ; 95 \% \mathrm{CI}: 0.4$ to $1.3 ; P=0.27)$ were not associated with the odds of becoming and remaining lame during the dry period. Model details are provided on Supplemental Table S3 (https://doi.org/10.3168/jds .2019-16741).

\section{Risk Factors for Lameness Cure}

Parity and BCS were associated with the odds of curing lameness during the dry period (Table 7). Multiparous cows had lower odds of curing lameness compared

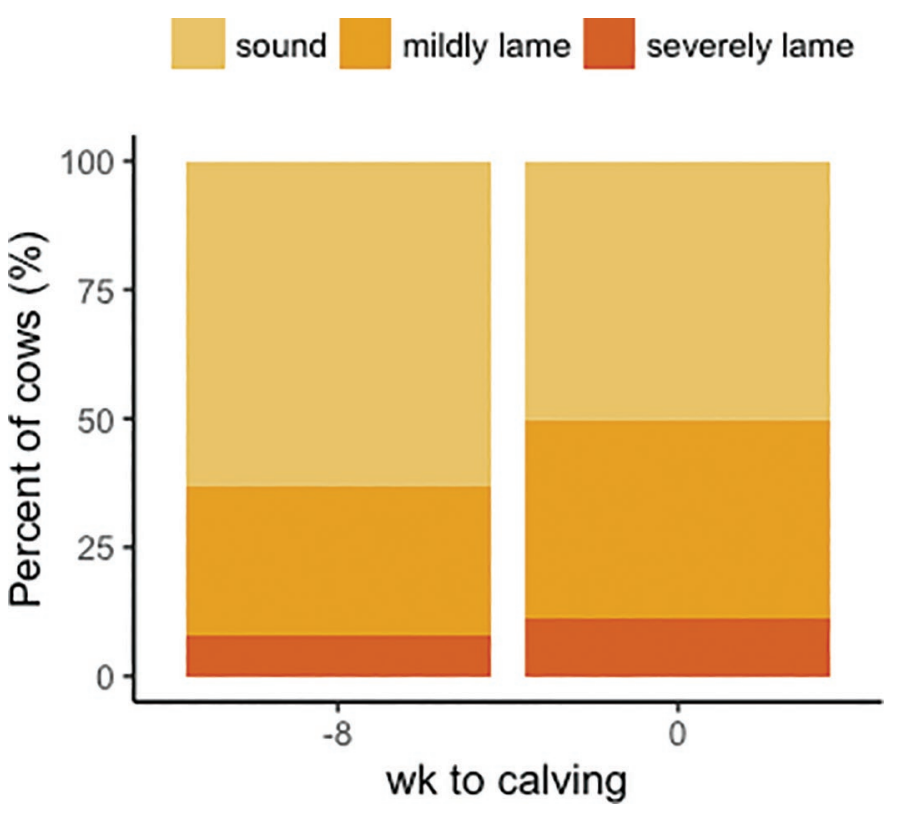

Figure 2. Prevalence of lameness at first assessment performed on wk $8( \pm 1)$ before calving and prevalence of lameness on the week of calving (calving day included). 
Table 4. Prevalence of hoof lesions from d 100 before calving to the day of calving by period (before and after enrollment) and parity for 205 dairy cows in 6 dairy farms in the Fraser Valley region in British Columbia, Canada $^{1}$

\begin{tabular}{llccc}
\hline \multirow{2}{*}{$\begin{array}{l}\text { Hoof-trimming } \\
\text { period }\end{array}$} & Lesion type & Primiparous & Multiparous & $\begin{array}{c}\text { Prevalence } \\
(\%)\end{array}$ \\
\cline { 3 - 4 } Before enrollment & Noninfectious $^{3}$ & 2 & 8 & 10 \\
& Infectious $^{4}$ & 3 & 7 & 10 \\
Nofter enrollment & No lesions $^{\text {Noninfectious }}{ }^{3}$ & 95 & 85 & 80 \\
& Infectious $^{4}$ & 0 & 2 & 2 \\
& No lesions & 3 & 5 & 8 \\
& & 97 & 93 & 90 \\
\hline
\end{tabular}

${ }^{1}$ Hoof trimming performed by a professional hoof trimmer. Lesion assessment based on Alberta hoof lesion atlas (www.dairyhoofhealth.info/Lesion-Severity-Guide-v0.7.pdf).

${ }^{2}$ Parity at the time of enrollment.

${ }^{3}$ Noninfectious include cows with severe sole hemorrhages, sole and toe ulcers, white line disease, and thin soles.

${ }^{4}$ Infectious lesions include cows with digital dermatitis, interdigital dermatitis, and foot rot.

with primiparous cows, and thin cows (BCS <3.0) had lower odds of curing lameness compared with cows in good condition (BCS 3.0 to 3.5). Over condition (BCS $>3.5$ ) was not associated with changes in odds of curing lameness.

\section{Risk Factors for Chronic Lameness}

In the first model that included all cows regardless of whether they were trimmed before enrollment, the interaction between parity and hoof-trimming before

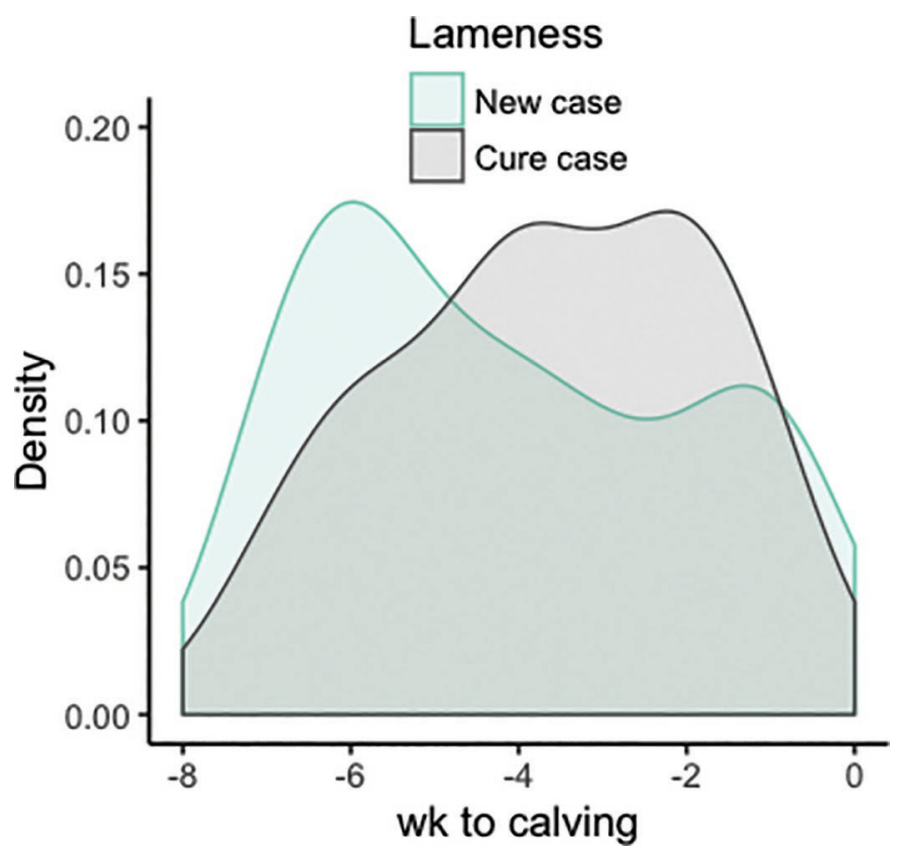

Figure 3. The distribution of new cases and cure cases of lameness during the dry period. Density was calculated based on the number of cases per week divided by the total number of cases during the dry period for the respective category. enrollment was associated with the odds of being chronically lame. The estimates, confidence intervals, and $P$-values for all variables included in the model are presented on Table 8. The interaction follows the same pattern described for the onset of lameness; multiparous cows had higher odds of being chronically lame if they were trimmed before enrollment, whereas primiparous cows had lower odds of being chronically lame if they were trimmed before enrollment (see Figure 4b). Thin cows (BCS $<3$ ) had increased odds of being chronically lame compared with cows in good condition (BCS 3.0 to 3.5), whereas overconditioned cows did not differ from cows in good condition.

In the second model, which included only cows that were hoof-trimmed before enrollment, parity and lesion type were associated with the odds of chronic lameness. Multiparous cows had increased odds for chronic lameness $(\mathrm{OR}=10.8 ; 95 \%$ CI: 3.4 to $44.4 ; P<0.01)$ compared with primiparous cows. Cows diagnosed with noninfectious hoof lesions before enrollment also had increased odds for chronic lameness $(\mathrm{OR}=38.9 ; 95 \%$ CI: 5.8 to $822 ; P<0.01)$ compared with cows that were not diagnosed with any hoof lesion in the same period. Infectious lesion $(\mathrm{OR}=2.9 ; 95 \%$ CI: 0.6 to $16.6 ; P$ $=0.22$ ), days elapsed from hoof-trimming to enrollment $(\mathrm{OR}=1.0 ; 95 \% \mathrm{CI}: 0.9$ to $1.0 ; P=0.15)$, and estimated lactational milk production $(\mathrm{OR}=0.7 ; 95 \%$ CI: 0.4 to $1.3 ; P=0.50$ ) were not associated with the odds of chronic lameness during the dry period. Model details provided on Supplemental Table S4 (https://doi .org/10.3168/jds.2019-16741).

\section{DISCUSSION}

Our study is the first to describe incidence and cure rates (and risk) of lameness during the dry period. In this study we report both risk and rate to provide a 
Table 5. Epidemiological descriptors of lameness categories and median number of weeks lame during the dry period of 455 dairy cows from 6 dairy farms in the Fraser Valley region, British Columbia, Canada

\begin{tabular}{|c|c|c|c|c|c|}
\hline \multirow[b]{2}{*}{$\begin{array}{l}\text { Lameness } \\
\text { category }^{1}\end{array}$} & \multirow[b]{2}{*}{$\begin{array}{l}\text { Incidence } \\
\text { risk (\%) }\end{array}$} & \multirow[b]{2}{*}{$\begin{array}{c}\text { Proportion } \\
\text { per } \operatorname{group}^{2}(\%)\end{array}$} & \multicolumn{3}{|c|}{ Weeks lame } \\
\hline & & & Median & $\begin{array}{c}\text { 1st } \\
\text { quartile }\end{array}$ & $\begin{array}{c}\text { 3rd } \\
\text { quartile }\end{array}$ \\
\hline \multicolumn{6}{|l|}{ Starting as sound } \\
\hline Became lame & 50 & - & 4 & 2 & 5 \\
\hline Recovered & 34 & 11 & 2 & 2 & 4 \\
\hline Remained lame & 66 & 21 & 4 & 2.5 & 6 \\
\hline Always sound & 50 & 31 & - & - & - \\
\hline \multicolumn{6}{|l|}{ Starting as lame } \\
\hline Cured & 36 & - & 5 & 3.75 & 7 \\
\hline Reoccurred & 37 & 5 & 6 & 4.25 & 7 \\
\hline Remained cured & 63 & 8 & 5 & 3 & 7 \\
\hline Chronically lame & 64 & 24 & - & - & - \\
\hline
\end{tabular}

comprehensive level of detail of the lameness new cases and cure cases. While risk provides the exact proportion of cows becoming lame or curing lame during the dry period, rates provide a measurement that can be generalized. An extrapolation of our data suggests a yearly incidence rate of 4.2 cases/cow per yr. In a recent study, using weekly gait scoring in a research dairy herd, Randall et al. (2018) report lactational lameness incidence 7.4 cases/cow per yr. In other studies, lactational incidence rates of lameness ranged from 0.1 to 1.7 cases/cow per yr in a study of 37 dairy farms (Clarkson et al., 1996) and an average of 0.7 cases/ cow per yr in another study of 5 dairy farms (Green et al., 2002). It is worth noting that these 2 studies did not assess lameness as frequently as we did. Following our gait assessment schedule and the application of our lameness definition, we were able to detect cases of lameness of short duration (i.e., cases lasting 2 to 3 wk). Moreover, we did not enroll late-gestation heifers, a group of animals with a lower lameness prevalence compared with parous cow (Calderon and Cook, 2011). Given our case definition, and the inclusion of only primiparous and older cows, it is not surprising that we found a high incidence of lameness.

Few studies have reported cure from lameness during the dry period. For instance, Archer et al. (2010) reported that lameness cure risk (i.e., proportion of cows that were lame before dry-off and were sound after calving) was $18 \%$. Our results show that $36 \%$ of cows cured lameness during the dry period; however, of these, $37 \%$ reoccurred in the weeks before calving. Lim et al. (2015) reported a lactational cure risk of $81 \%$, but these authors followed cows for a much longer period of time; $88 \%$ of cure cases occurred within $45 \mathrm{~d}$ after the lameness episode. Perhaps if we had followed all enrolled cows beyond the dry period, a higher proportion of lameness cases would have had time to recover. Nonetheless, our results suggest that the dry period may not be long enough for some cows to recover from lameness.

A total of $11 \%$ of the cows developed short cases of lameness; these cows were lame for $<4$ wk during the dry period. In a companion study (Eriksson et al., 2019), we suggest that using 2 consecutive gait scores to classify lameness cases can decrease misclassification, while still detecting lameness cases of short duration. Little is known about the effect of short lameness cases; however, it is likely that even short cases of duration increase the chances of future lameness cases (Randall et al., 2018).

We graphically assessed the distribution of new lameness cases and lameness cure cases during the dry period (see Figure 3). A lower proportion of cases at the beginning of the dry period and around calving were expected, given that our lameness case definition required 2 consecutive scores. Although we observed a decrease in the proportion of new cases of lameness over the dry period, we also observed a higher proportion of cure cases later on during the same period. We speculate that these patterns may indicate that there is a shift in the risk of becoming lame throughout the dry period. Future studies may further investigate this idea by looking at risk factors for the development and cure cases of lameness in the far-off and close-up periods separately.

In contrast to the low prevalence of lameness around dry-off reported by Foditsch et al. (2016), our results show a high prevalence of lameness around dry-off and calving in line with those described by Archer et al. (2010) that reported lameness prevalence of 66 and 
$73 \%$ in the month before dry-off and the month after calving, respectively. Discrepancies in lameness prevalence may be due to herd selection criteria and gait scoring methodology used.

In the current study, cows that were lame in the week before calving were also more likely to be lame around wk 2 and 8 after calving. This result suggests that a

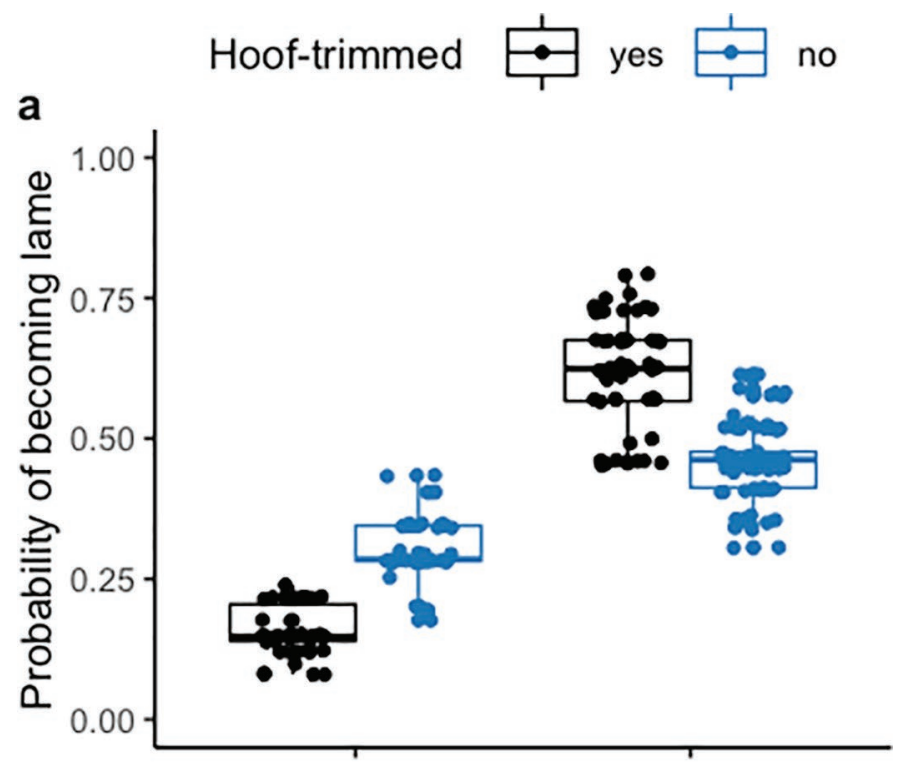

b

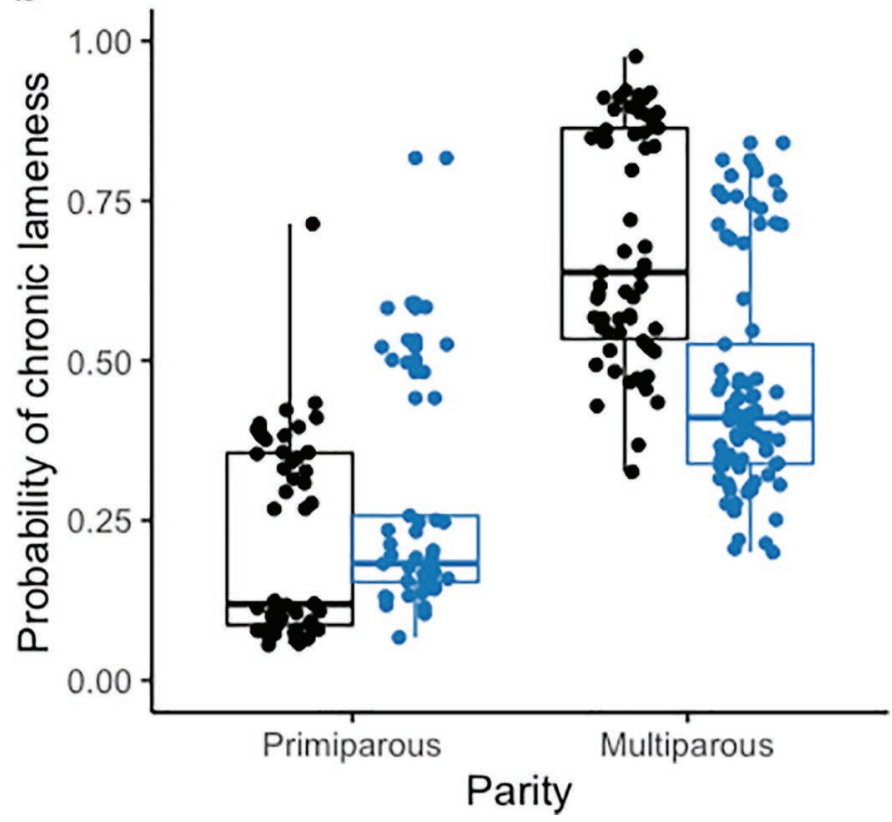

Figure 4. Estimated probabilities for each cow (single dots) of becoming lame (a) or chronically lame (b) from the interaction between the predictors hoof-trimming before enrollment and parity. Bars within the box represent median; bottom and top of the box bars represent first and third quartiles, respectively. Whiskers extend to the most extreme value no more than 1.5 times the interquartile range. large proportion of lameness during the first months of lactation may have been carried over from the dry period, likely contributing to the high prevalence of lameness in early lactation (Green et al., 2002; Bicalho et al., 2007).

Despite the fact that previous lameness events are known to be a major risk factor for future lameness events (Randall et al., 2018), we were unable to include this information in our models given that our work took place on commercial dairy farms that do not routinely collect lameness events. We encourage the reader to consider this when interpreting our findings. In the current study, hoof-trimming before the enrolment period was associated with decreased odds of becoming lame and chronic lameness for primiparous but not multiparous cows. Randomized studies assessing the effectiveness of hoof-trimming on future lameness occurrence (Manske et al., 2002) or lameness cure shortly after trimming (Thomas et al., 2015, 2016) did not report this interaction. Cows with a previous history of claw lesions and lameness are more likely to develop subsequent cases of lameness (Hirst et al., 2002; Randall et al., 2018), possibly explaining why older cows are more likely to be lame (Amory et al., 2008; Foditsch et al., 2016). We further speculate that farmers could be selecting (consciously or not) multiparous cows for trimming that had a history of claw lesions and lameness. Conversely, primiparous cows may have not yet developed lameness (or claw lesions), and thus were better able to benefit from the preventive effect of hoof-trimming. Hoof-trimming treatment outcome depends on when trimming is performed in relation to the onset of lameness (Leach et al., 2012; Thomas et al., 2016); therefore, if multiparous cows have been previously lame, or chronically lame, it is less likely that hoof-trimming would be effective. Further research should investigate the effect of preventive trimming before dry-off for cows with and without previous history of lameness and hoof lesions.

We found that cows with noninfectious lesions were more likely to be chronically lame during the dry period compared with cows with no lesions. Noninfectious lesions have been associated with the formation of bone protrusions (i.e., osteomas) in the caudal region of the distal phalanx (Newsome et al., 2016); their presence may explain why cows with previous noninfectious lesions would be at increased risk of developing subsequent cases of lesions and lameness (Hirst et al., 2002; Foditsch et al., 2016).

Body condition at dry-off has been positively associated with digital cushion thickness (Machado et al., 2011) and is thought to reduce the risk of the development of noninfectious lesions (see review: Bicalho and Oikonomou, 2013). Accordingly, several studies have shown that having low BCS is associated with the de- 
Table 6. Multilevel logistic regression model of risk factors for becoming lame during the dry period in 237 cows in 6 freestall dairy herds in British Columbia, Canada

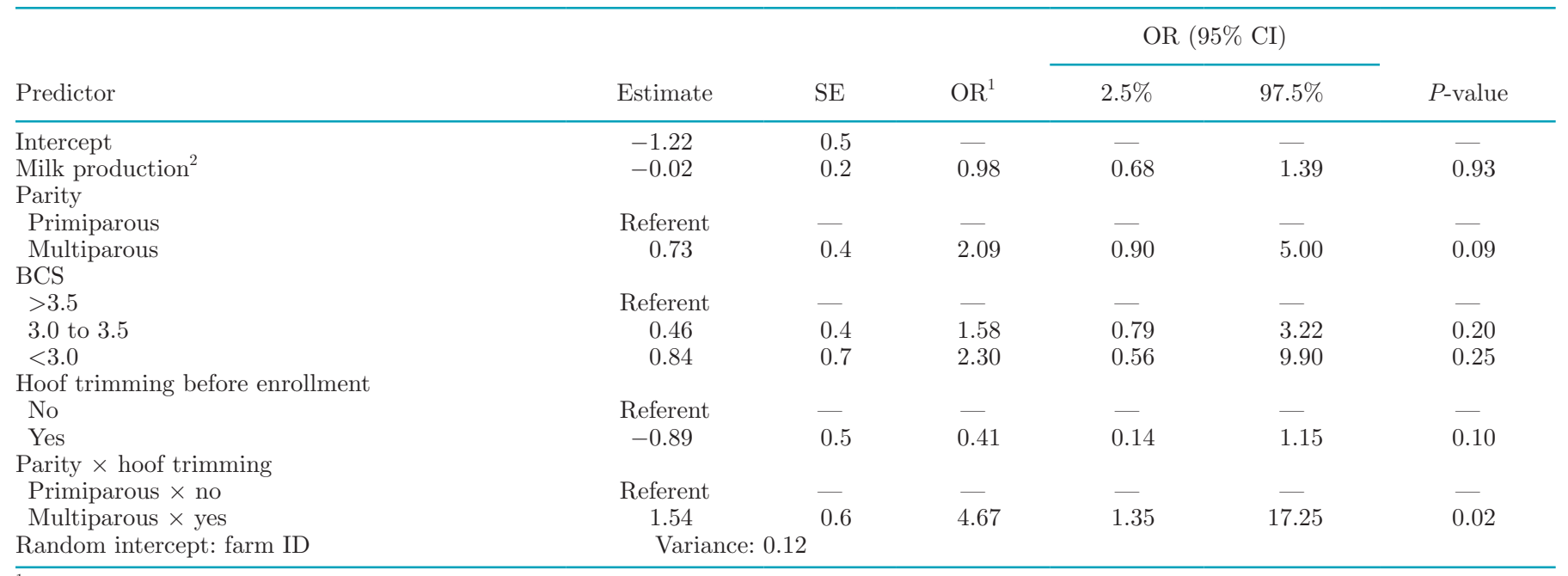

${ }^{1} \mathrm{OR}=$ odds ratio.

${ }^{2}$ Scaled variable.

velopment of lameness (Lim et al., 2015; Randall et al., 2015). As expected, we found that low body condition around dry-off was associated with higher odds of chronic lameness and lower odds of curing from being lame during the dry period. However, low body condition was not associated with odds of becoming lame. Perhaps, the low number of thin cows available may have made it difficult to detect such effect, given that body condition only contributes slightly to the risk of lameness development (Randall et al., 2018).

Previous lactation milk production was not associated with lameness onset, lameness cure, or chronic lameness. Because our sample size to measure such association was limited, failure to find an association between lameness and milk production may be due to type II errors. Previous studies have reported that high producing cows are more likely to become lame (Green et al., 2002; Archer et al., 2010); however, these studies were limited to lactating dairy cows. Cows with high milk yield have different time budgets and spend more time standing than lower producing cows (Norring et al., 2012). Increased standing time may increase the chances of lameness development through the development of claw lesions (Chapinal et al., 2009; Proudfoot

Table 7. Multilevel logistic regression model of risk factors for curing lameness during the dry period in 146 cows in 6 freestall dairy herds in British Columbia, Canada

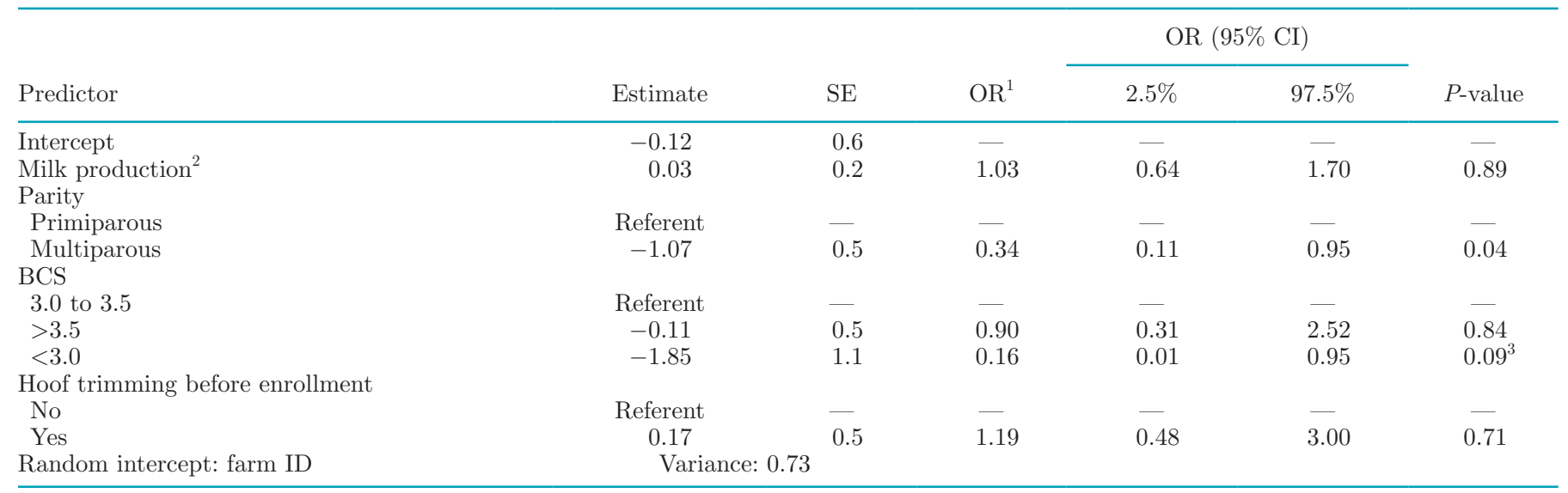

${ }^{1} \mathrm{OR}=$ odds ratio.

${ }^{2}$ Scaled variable.

${ }^{3}$ Discrepancy between $P$-value and $95 \%$ CI is because of different methods for estimating $P$ (Wald method) and 95\% CI (profile likelihood method). 
Table 8. Multilevel logistic regression model of risk factors for chronic lameness during the dry period in 250 cows in 6 freestall dairy herds in British Columbia, Canada

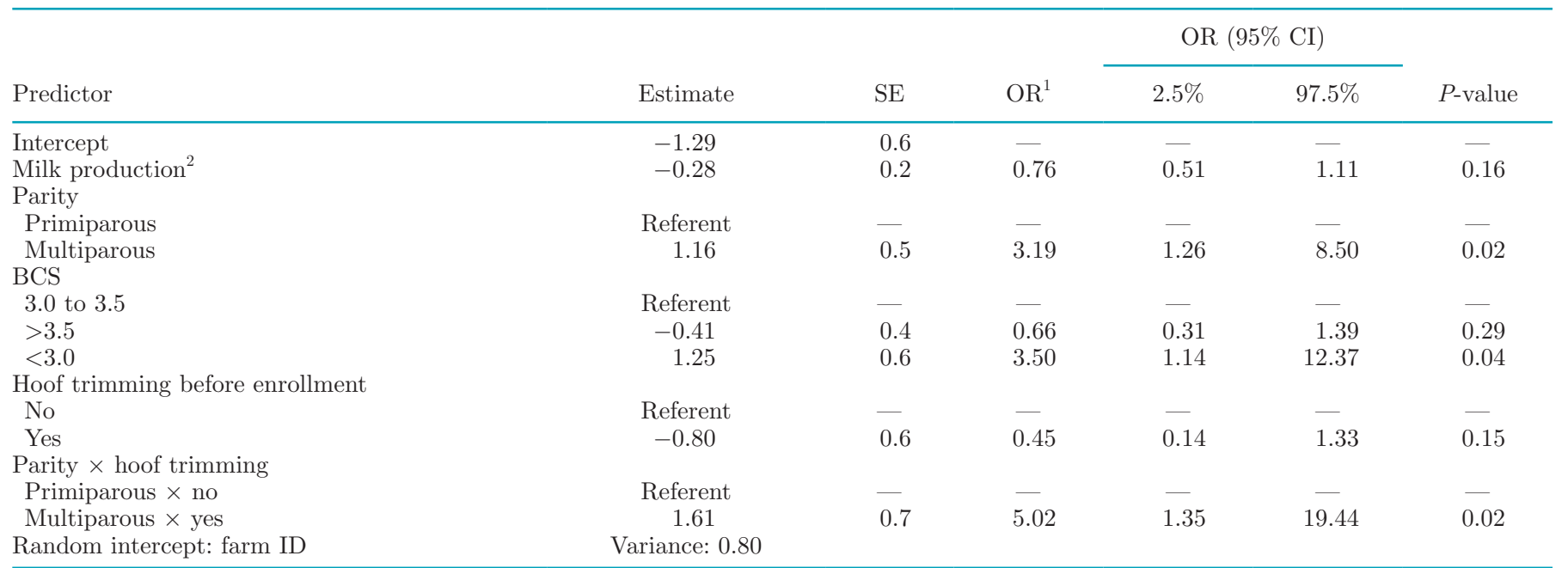

${ }^{1} \mathrm{OR}=$ odds ratio.

${ }^{2}$ Scaled variable.

et al., 2010). An alternative hypothesis for the lack of association between milk production and lameness during the dry period in the current study may be a result of differences in the time budget between dry cows and lactating cows. To our knowledge, this hypothesis remains untested.

Although this study was not designed to measure the association between lameness onset/cure and herd-level management practices, we noted none of the farms applied measures for improving claw health to the nonlactating animals. Failure to include dry cows may have influenced the onset of lameness during the dry period. Future studies should examine the effect of practices such as foot baths, routine gait scoring, and trimming on lameness during the dry period.

\section{CONCLUSIONS}

A high incidence of lameness was observed during the dry period. Hoof trimming before the dry-period reduced the risk of lameness for primiparous but not for multiparous cows. Low body condition at dry-off and noninfectious hoof lesions in the weeks before dry-off were associated with chronic lameness during the dry period.

\section{ACKNOWLEDGMENTS}

We thank Samantha Jung, Paige Macdonald, and Wali Sahar (Animal Welfare Program) for their help during data collection, the participating farmers for their time and allowing us to carry this project on their properties, the hoof-trimmers involved in the project, and Martin Stigge (Vancouver, BC, Canada) for helping with software development and $\mathrm{R}$ code support. During this project RRD was supported by the Science Without Borders Program (CNPq, National Council for Scientific and Technological Development, Brazil). HKE was supported by Tetra-Laval through the Sweden-America Foundation (Stockholm, Sweden). Funding for this project has been provided by the BC Dairy Association through the Dairy Industry Research and Education Committee, and the Agriculture and Agri-Food Canada and the BC Ministry of Agriculture through the Canada-BC Agri-Innovation Program under Growing Forward 2, a federal-provincial-territorial initiative. The program is delivered by the Investment Agriculture Foundation of BC. Opinions expressed in this document are those of the author and not necessarily those of the governments of Canada and British Columbia or the Investment Agriculture Foundation of BC. The governments of Canada and British Columbia, and the Investment Agriculture Foundation of BC, and their directors, agents, employees, or contractors will not be liable for any claims, damages, or losses of any kind whatsoever arising out of the use of, or reliance upon, this information. General funding for the University of British Columbia Animal Welfare Program is provided by Canada's Natural Sciences and Engineering Research Council Industrial Research Chair Program (Ottawa, ON, Canada) with contributions from Dairy Farmers of Canada (Ottawa, ON, Canada), British Columbia Dairy Association (Burnaby, BC, Canada), Westgen Endowment Fund (Milner, BC, Canada), Intervet Canada Corporation (Kirkland, QC, Canada), Zoetis (Kirkland, QC, Canada), Novus 
International Inc. (Oakville, ON, Canada), BC Cattle Industry Development Fund (Kamloops, BC, Canada), Alberta Milk (Edmonton, AB, Canada), Valacta (St Anne-de-Bellevue, QC, Canada), and CanWest DHI (Guelph, ON, Canada).

\section{REFERENCES}

Amory, J. R., Z. E. Barker, J. L. Wright, S. A. Mason, R. W. Blowey, and L. E. Green. 2008. Associations between sole ulcer, white line disease and digital dermatitis and the milk yield of 1824 dairy cows on 30 dairy cow farms in England and Wales from February 2003-November 2004. Prev. Vet. Med. 83:381-391. https://doi .org/10.1016/j.prevetmed.2007.09.007.

Archer, S. C., M. J. Green, and J. N. Huxley. 2010. Association between milk yield and serial locomotion score assessments in UK dairy cows. J. Dairy Sci. 93:4045-4053. https://doi.org/10.3168/ jds.2010-3062.

Bicalho, R. C., and G. Oikonomou. 2013. Control and prevention of lameness associated with claw lesions in dairy cows. Livest. Sci. 156:96-105. https://doi.org/10.1016/j.livsci.2013.06.007.

Bicalho, R. C., F. Vokey, H. N. Erb, and C. L. Guard. 2007. Visual locomotion scoring in the first seventy days in milk: Impact on pregnancy and survival. J. Dairy Sci. 90:4586-4591. https://doi .org/10.3168/jds.2007-0297.

Booth, C. J., L. D. Warnick, Y. T. Gröhn, D. O. Maizon, C. L. Guard, and D. Janssen. 2004. Effect of lameness on culling in dairy cows. J. Dairy Sci. 87:4115-4122. https://doi.org/10.3168/jds.S0022 $-0302(04) 73554-7$.

Byrt, T. J. Bishop, and J. B. Carlin. 1993. Bias, prevalence and kappa. J. Clin. Epidemiol. 46:423-429.

Calderon, D. F., and N. B. Cook. 2011. The effect of lameness on the resting behavior and metabolic status of dairy cattle during the transition period in a freestall-housed dairy herd. J. Dairy Sci. 94:2883-2894. https://doi.org/10.3168/jds.2010-3855.

Chapinal, N., A. M. de Passillé, J. Rushen, and S. Wagner. 2010. Automated methods for detecting lameness and measuring analgesia in dairy cattle. J. Dairy Sci. 93:2007-2013. https://doi.org/10 .3168/jds.2009-2803.

Chapinal, N., A. M. de Passillé, D. M. Weary, M. A. G. von Keyserlingk, and J. Rushen. 2009. Using gait score, walking speed, and lying behavior to detect hoof lesions in dairy cows. J. Dairy Sci. 92:4365-4374. https://doi.org/10.3168/jds.2009-2115.

Cicchetti, D. V. 1994. Guidelines, criteria, and rules of thumb for evaluating normed and standardized assessment instruments in psychology. Psychol. Assess. 6:284-290. https://doi.org/10.1037/ 1040-3590.6.4.284

Clarkson, M. J., D. Y. Downham, W. B. Faull, J. W. Hughes, F. J. Manson, J. B. Merritt, R. D. Murray, W. B. Russell, J. E Sutherst, and W. R. Ward. 1996. Incidence and prevalence of lameness in dairy cattle. Vet. Rec. 138:563-567. https://doi.org/ $10.1136 / v r .138 .23 .563$

Cohen, J. 1968. Weighted kappa: Nominal scale agreement provision for scaled disagreement or partial credit. Psychol. Bull. 70:213 220. https://doi.org/10.1037/h0026256.

Dairy Farmers of Canada. 2009. Code of Practice for the Care and Handling of Dairy Cattle. Accessed Sep. 29, 2018. https://www .nfacc.ca/pdfs/codes/dairy_code_of_practice.pdf.

Dohoo, I. R., M. Wayne, and H. Stryhn. 2012. Methods in Epidemiologic Research. 2nd ed. VER Inc., Charlottetown, Canada.

Eriksson, H. K., R. R. Daros, M. A. G. von Keyserlingk, and D. M. Weary. 2019. Effects of case definition and assessment frequency on lameness incidence estimates in dairy cattle. J. Dairy Sci. 102:XXX-XXX. https://doi.org/10.3168/jds.2019-16426.

Ferguson, J. D., D. T. Galligan, and N. Thomsen. 1994. Principal descriptors of body condition score in Holstein cows. J. Dairy Sci. 77:2695-2703. https://doi.org/10.3168/jds.S0022-0302(94)77212 $-\mathrm{X}$.
Flower, F. C., and D. M. Weary. 2006. Effect of hoof pathologies on subjective assessments of dairy cow gait. J. Dairy Sci. 89:139-146. https://doi.org/10.3168/jds.S0022-0302(06)72077-X.

Foditsch, C., G. Oikonomou, V. S. Machado, M. L. Bicalho, E. K Ganda, S. F. Lima, R. Rossi, B. L. Ribeiro, A. Kussler, and R. C. Bicalho. 2016. Lameness prevalence and risk factors in large dairy farms in upstate New York. Model development for the prediction of claw horn disruption lesions. PLoS One 11:e0146718. https:// doi.org/10.1371/journal.pone.0146718.

Green, L. E., V. J. Hedges, Y. H. Schukken, R. W. Blowey, and A. J. Packington. 2002. The impact of clinical lameness on the milk yield of dairy cows. J. Dairy Sci. 85:2250-2256. https://doi.org/10 $.3168 /$ jds.S0022-0302(02)74304-X.

Hallgren, K. A. 2012. Computing inter-rater reliability for observational data: An overview and tutorial. Tutor. Quant. Methods Psychol. 8:23-34.

Hernandez, J. A., E. J. Garbarino, J. K. Shearer, C. A. Risco, and W. W. Thatcher. 2005. Comparison of the calving-to-conception interval in dairy cows with different degrees of lameness during the prebreeding postpartum period. J. Am. Vet. Med. Assoc. 227:1284-1291. https://doi.org/10.2460/javma.2005.227.1284.

Hirst, W. M., R. Murray, W. Ward, and N. French. 2002. A mixedeffects time-to-event analysis of the relationship between firstlactation lameness and subsequent lameness in dairy cows in the UK. Prev. Vet. Med. 54:191-201. https://doi.org/10.1016/S0167 $-5877(02) 00021-1$

Hosmer, D. W., and S. Lemeshow. 1980. Goodness of fit tests for the multiple logistic regression model. Commun. Stat. Theory Methods 9:1043-1069. https://doi.org/10.1080/03610928008827941.

Leach, K. A., D. A. Tisdall, N. J. Bell, D. C. J. Main, and L. E. Green. 2012. The effects of early treatment for hindlimb lameness in dairy cows on four commercial UK farms. Vet. J. 193:626-632. https:// doi.org/10.1016/j.tvjl.2012.06.043.

Lim, P. Y., J. N. Huxley, J. A. Willshire, M. J. Green, A. R. Othman, and J. Kaler. 2015. Unravelling the temporal association between lameness and body condition score in dairy cattle using a multistate modelling approach. Prev. Vet. Med. 118:370-377. https:// doi.org/10.1016/j.prevetmed.2014.12.015.

Machado, V. S., L. S. Caixeta, and R. C. Bicalho. 2011. Use of data collected at cessation of lactation to predict incidence of sole ulcers and white line disease during the subsequent lactation in dairy cows. Am. J. Vet. Res. 72:1338-1343. https://doi.org/10.2460/ajvr .72 .10 .1338

Manske, T., J. Hultgren, and C. Bergsten. 2002. The effect of claw trimming on the hoof health of Swedish dairy cattle. Prev. Vet. Med. 54:113-129. https://doi.org/10.1016/S0167-5877(02)00020 $-\mathrm{X}$.

Miguel-Pacheco, G. G., H. J. Thomas, J. N. Huxley, R. F. Newsome, and J. Kaler. 2017. Effect of claw horn lesion type and severity at the time of treatment on outcome of lameness in dairy cows. Vet. J. 225:16-22. https://doi.org/10.1016/j.tvjl.2017.04.015.

Murray, R. D., D. Y. Downham, M. J. Clarkson, W. B. Faull, J. W. Hughes, F. J. Manson, J. B. Merritt, W. B. Russell, J. E. Sutherst, and W. R. Ward. 1996. Epidemiology of lameness in dairy cattle: description and analysis of foot lesions. Vet. Rec. 138:586-591. https://doi.org/10.1136/vr.138.24.586.

Newsome, R., M. J. Green, N. J. Bell, M. G. G. Chagunda, C. S. Mason, C. S. Rutland, C. J. Sturrock, H. R. Whay, and J. N. Huxley. 2016. Linking bone development on the caudal aspect of the distal phalanx with lameness during life. J. Dairy Sci. 99:4512-4525. https://doi.org/10.3168/jds.2015-10202.

Norring, M., A. Valros, and L. Munksgaard. 2012. Milk yield affects time budget of dairy cows in tie-stalls. J. Dairy Sci. 95:102-108. https://doi.org/10.3168/jds.2010-3458.

Potterton, S. L., N. J. Bell, H. R. Whay, E. A. Berry, O. C. D. Atkinson, R. S. Dean, D. C. J. Main, and J. N. Huxley. 2012. A descriptive review of the peer and non-peer reviewed literature on the treatment and prevention of foot lameness in cattle published between 2000 and 2011. Vet. J. 193:612-616. https://doi.org/10 $.1016 / j . t v j l .2012 .06 .040$ 
Proudfoot, K. L., D. M. Weary, and M. A. G. von Keyserlingk. 2010. Behavior during transition differs for cows diagnosed with claw horn lesions in mid lactation. J. Dairy Sci. 93:3970-3978. https:// doi.org/10.3168/jds.2009-2767.

R Core Team. 2019. R: A language and environment for statistical computing. R Foundation for Statistical Computing, Vienna, Austria. https://www.r-project.org/.

Randall, L. V., M. J. Green, M. G. G. Chagunda, C. Mason, S. C. Archer, L. E. Green, and J. N. Huxley. 2015. Low body condition predisposes cattle to lameness: An 8-year study of one dairy herd. J. Dairy Sci. 98:3766-3777. https://doi.org/10.3168/jds.2014-8863.

Randall, L. V., M. J. Green, L. E. Green, M. G. G. Chagunda, C. Mason, S. C. Archer, and J. N. Huxley. 2018. The contribution of previous lameness events and body condition score to the occurrence of lameness in dairy herds: A study of 2 herds. J. Dairy Sci. 101:1311-1324. https://doi.org/10.3168/jds.2017-13439.

RStudio Team. 2016. RStudio: Integrated Development Environment for R. RStudio Inc., Boston, MA. http//www.rstudio.com/.

Solano, L., H. W. Barkema, E. A. Pajor, S. Mason, S. J. LeBlanc, J. C. Zaffino Heyerhoff, C. G. R. Nash, D. B. Haley, E. Vasseur, D. Pellerin, J. Rushen, A. M. de Passillé, and K. Orsel. 2015. Prevalence of lameness and associated risk factors in Canadian HolsteinFriesian cows housed in freestall barns. J. Dairy Sci. 98:6978-6991. https://doi.org/10.3168/jds.2015-9652.

Tadich, N., E. Flor, and L. Green. 2010. Associations between hoof lesions and locomotion score in 1098 unsound dairy cows. Vet. J. 184:60-65. https://doi.org/10.1016/j.tvjl.2009.01.005.
Thomas, H. J., G. G. Miguel-Pacheco, N. J. Bollard, S. C. Archer, N. J. Bell, C. Mason, O. J. R. Maxwell, J. G. Remnant, P. Sleeman, H. R. Whay, and J. N. Huxley. 2015. Evaluation of treatments for claw horn lesions in dairy cows in a randomized controlled trial. J. Dairy Sci. 98:4477-4486. https://doi.org/10.3168/jds.2014-8982.

Thomas, H. J., J. G. Remnant, N. J. Bollard, A. Burrows, H. R. Whay, N. J. Bell, C. Mason, and J. N. Huxley. 2016. Recovery of chronically lame dairy cows following treatment for claw horn lesions: A randomised controlled trial. Vet. Rec. 178:116. https://doi.org/10 $.1136 /$ vr.103394.

von Keyserlingk, M. A. G., A. Barrientos, K. Ito, E. Galo, and D. M. Weary. 2012. Benchmarking cow comfort on North American freestall dairies: Lameness, leg injuries, lying time, facility design, and management for high-producing Holstein dairy cows. J. Dairy Sci. 95:7399-7408. https://doi.org/10.3168/jds.2012-5807.

\section{ORCIDS}

Ruan R. Daros @ https://orcid.org/0000-0003-2331-1648 Daniel M. Weary @ https://orcid.org/0000-0002-0917-3982 Marina A. G. von Keyserlingk (i) https://orcid.org/0000-0002-1427 $-3152$ 